\title{
Database on the coverage of the "Bolsa-Família" conditioning cash-transfer program: Brazil, 2005 to 2021
}

\author{
Lais Baroni ${ }^{1,2}$, Ronaldo Fernandes Santos Alves ${ }^{2}$, Cristiano Siqueira Boccolini ${ }^{2}$, Rebecca Salles ${ }^{1,3}$, Raquel Gritz ${ }^{3}$, \\ Balthazar Paixão $0^{1,3}$ and Patricia de Moraes Mello Boccolini ${ }^{2,4^{*}}$ (])
}

\begin{abstract}
Objectives: The "Bolsa-Família" Program (PBF) is a Brazilian conditional cash-transfer program in which families should comply with health, education, and social assistance conditionalities. The program aims to fight poverty and hunger, promoting nutrition and health services for low-income populations. This paper presents a database on the coverage of monitoring and compliance with the PBF health conditionalities in Brazil from January 2005 to July 2021.
\end{abstract}

Data description: Database on the PBF conditioning cash-transfer program coverage in Brazil from 2005 to 2021. It comprises information on the number of families benefited, health conditionalities, and the follow-up on vaccination and nutrition of children under seven years old. The cities and semesters are the minimal aggregation units.

Keywords: Child Health, Social programs, Nutrition Programs and Policies, Vaccination Coverage, Health Information Systems, Database

\section{Objective}

The "Bolsa-Família" Program (PBF) is a Brazilian direct cash transfer program in which families should comply with conditionalities on health, education, and social assistance [1,2]. The PBF aims to protect the human rights of vulnerable families, interrupting the intergenerational cycle of poverty. The PBF contemplates families with monthly per capita income up to $\mathrm{R} \$ 89.00$ (U\$17.5) or families with monthly per capita income between $\mathrm{R} \$ 89.01$ and $\mathrm{R} \$ 178.00$ (U\$17.5 to U\$34.9) that have pregnant women or children up to 17 years old [2]. The primary health care workers of Unified Health System (SUS) are responsible for monitoring and recording compliance with the PBF health conditionalities [2, 3].

It is mandatory to monitor children under seven years old, women from 14 to 44 years old, and pregnant women

\footnotetext{
*Correspondence: patricia.boccolini@icict.fiocruz.br

${ }^{4}$ Petropolis Medical School, UNIFASE, Petrópolis, Brazi

Full list of author information is available at the end of the article
}

regarding nutritional status, vaccination, and prenatal and postpartum care [4]. All information about the beneficiaries is registered in the PBF in Health System (BFA) of the Ministry of Health [3]. Regular monitoring of these conditionalities contributes to fulfilling constitutional health commitments and national health policies, improving health care and the population's health and nutrition conditions. Additionally, the monitoring makes it possible to identify which families have difficulty accessing health services. Based on this information, the government can act to improve actions and services aimed at the most vulnerable populations. The PBF contributes to the reduction of mortality in under- $5 \mathrm{~s}$, especially deaths attributed to poverty, such as malnutrition and diarrhea [5].

We present a dataset that harmonizes, processes, validates, and enriches the data of the BFA System. The dataset is part of the COVAC [6] and MATRECI [7] studies and will be integrated with data on primary health care coverage and preventable infant mortality in Brazil. 
Table 1 Overview of data files/datasets

\begin{tabular}{llll}
\hline Label & Name of data file/dataset & File type (file extension) & Data repository and identifier \\
\hline Dataset 1 & pbf_health_data_raw & zipped (.zip) & Synapse: https://doi.org/10.7303/syn25884313 [8] \\
Dataset 2 & pbf_health_crude & zipped (.zip) & Synapse: https://doi.org/10.7303/syn25884313 [8] \\
Dataset 3 & pbf_health_full_epi_pt & delimited text (.csv) & Synapse: https://doi.org/10.7303/syn25884313 [8] \\
Dataset 4 & pbf_health_full_epi_en & delimited text (.csv) & Synapse: https://doi.org/10.7303/syn25884313 [8] \\
Data file 1 & pbf_health_overview & excel (.xlsx) & Synapse: https://doi.org/10.7303/syn25884313 [8] \\
Data file 2 & pbf_health_dataselfie_pt & HTML (.html) & Synapse: https://doi.org/10.7303/syn25884313 [8] \\
Data file 3 & pbf_health_dataselfie_en & HTML (.html) & Synapse: https://doi.org/10.7303/syn25884313 [8] \\
Data file 4 & script_pbf_health_ingestion & R code (.rmd) & Synapse: https://doi.org/10.7303/syn25884313 [8] \\
Data file 5 & script_pbf_health_analysis & R code (.rmd) & Synapse: https://doi.org/10.7303/syn25884313 [8] \\
Data file 6 & pbf_health_tables & excel (.xlsx) & Synapse: https://doi.org/10.7303/syn25884313 [8] \\
Data file 7 & pbf_health_figures & Portable document (.pdf) & Synapse: https://doi.org/10.7303/syn25884313 [8] \\
\hline
\end{tabular}

\section{Data description}

Coverage data for monitoring and compliance with PBF health conditionalities by municipality, semester, and year were extracted from the BFA System on July 9, 2021. The BFA System data are available on the former BFA platform $^{1}$ (2005/1 to 2018/1) and on the current e-Gestor AB platform ${ }^{2}$ (2018/2 onwards). The data extraction resulted in 33 files (.csv format), covering January 2005 to June 2021. These files were compiled and processed through a routine developed in the free and open-source software R.

This report provides 37 datasets and 7 data files. The 33 original databases (pbf_health_data_raw.zip) and two crude databases ( $p b f$ health_crude.zip) - formed by the simple combination of the original files from each BFA platform - are in a compressed folder. Processed databases are available in Portuguese (pbf_health_full_ epi_pt.csv) and English (pbf_health_full_epi_en.csv). The Excel file 'pbf_health_overview.xlsx' includes Portuguese and English versions of the metadata and variable dictionary of the treated databases. The HTML files (pbf_health_dataselfie_*html) present statistical summaries of each treated database variable. $\mathrm{R}$ scripts hold the codes for the data ingestion/curation routine (script pbf_health_ingestion.rmd) and the data analysis routine (script_pbf_health_analysis.rmd). The files 'pbf_health_ tables.xlsx' and 'pbf_health_figures.pdf gather, respectively, the tables and views generated in the data analysis step (Table 1).

\footnotetext{
${ }^{1}$ Until 2018, data from the PBF Health System (BFA) are available at: http:// bolsafamilia.datasus.gov.br/.

2 As of 2018, the BFA System data are available at: https://bfa.saude.gov.br/.
}

\section{Data construction}

Intake codes, curation, and descriptive data analysis were developed, examined and their results were compared to the information displayed on the e-Gestor AB platform. Data processing included the activities of (i) renaming the variables; (ii) separation of the field referring to the semester and year of competence; (iii) cleaning of numerical values, e.g., excluding special characters and (iv) enrichment of the municipal database with data aggregated by state, geographic region, and Brazil.

Two business rules were applied to the PBF monitoring coverage percentage indicators: (i) the coverage percentage will be equal to $0 \%$, whenever the denominator value is equal to 0 ; (ii) the coverage percentage will be equal to $100 \%$, whenever the numerator value is equal to or greater than the denominator value.

The database produced within the scope of this paper is stored in Synapse - in Portuguese (original language) to favor its use among Brazilian health professionals and researchers and in English for ease of use by the international community. The database has 184,801 observations and 21 variables.

In addition to geographic coverage, year, semester, name, and location code, there are six variables with the absolute numbers of children and families with a health profile, monitored and with up to date conditionalities, four variables on pregnant women, and six coverage variables. ${ }^{3}$ The numbers of families and children with a health profile comprised the denominators of the percentages of coverage of monitoring of the PBF's health conditionalities. The percentages of coverage of compliance with health conditionalities, in turn, have as denominators the number of families and children benefiting

\footnotetext{
${ }^{3}$ More detailed information can be found at https://www.synapse.org/Synap se:syn 25885153.
} 
from the PBF monitored by the SUS and, in the case of pregnant women, the total number of pregnant women located.

\section{Limitations}

- Possibility of analyzing only data aggregated at the geographic level.

- In 2019/1, the CNS field (National Health Registry number) was inserted in the BFA System of the e-Gestor $A B$ platform, favoring the migration of data from the e-SUS AB - which presumably led to an increase in the number of families beneficiaries in the BFA System.

- The estimation of the number of pregnant women in the municipalities was not checked.

- The data does not provide reasons for not following up on families with a health profile and non-compliance with the PBF's health conditionalities.

\section{Abbreviations}

PBF: "Bolsa Família" Program; BFA: "Bolsa Família" Program in Health; SUS: Unified Health System.

\section{Acknowledgements}

Not applicable.

\section{Authors' contributions}

Work conception and design: $C B, L B, P B, R A$,. Data acquisition, analysis and interpretation: $C B, L B, P B, R A$. Revision of the data workflow: $B P, C B, P B, R G, R S$. Wrote the first draft of the manuscript: $L B$, RA. Contributed to the writing of the manuscript: CB, PB. ICMJE criteria for authorship read and met: All authors. Agree with manuscript results and conclusion: All authors. All authors read and approved the final manuscript.

\section{Funding}

This work was supported, in whole or in part, by the Bill \& Melinda Gates Foundation [OPP1202042] and National Council for Scientific and Technological Development (CNPq). Under the grant conditions of the Foundation, a Creative Commons Attribution 4.0 Generic License has already been assigned to the Author Accepted Manuscript version that might arise from this submission. Furthermore, authors LB and RS were supported by the Coordenação de Aperfeiçoamento de Pessoal de Nível Superior - Brasil (CAPES) - Finance Code 001.

\section{Availability of data and materials}

The dataset generated during the current study and additional documentation is freely and openly available on the Synapse repository at https://doi.org/ 10.7303/syn25884313 [8]. Please see Table 1 for details.

\section{Declarations}

\section{Ethics approval and consent to participate}

The datasets used in this study were obtained from the open-data reports of the BFA System. The Ministry of Health of Brazil is committed to respect the ethical precepts and to guarantee the privacy and reliability of the data. According to Brazilian laws, the use of public and anonymized secondary data is waved from ethical approval.
Consent for publication

Not applicable.

\section{Competing interests}

The authors declare that they have no competing interests.

\section{Author details}

${ }^{1}$ Federal Center for Technological Education of Rio de Janeiro, CEFET/RJ, Rio de Janeiro, Brazil. ${ }^{2}$ Oswaldo Cruz Foundation, Fiocruz, Rio de Janeiro, Brazil. ${ }^{3}$ Platform of Data Science applied to Health (PCDaS), ICICT, Oswaldo Cruz Foundation, Fiocruz, Rio de Janeiro, Brazil. ${ }^{4}$ Petropolis Medical School, UNIFASE, Petrópolis, Brazil.

Received: 13 August 2021 Accepted: 12 November 2021

Published online: 27 November 2021

\section{References}

1. Brasil,. Lei extn ${ }^{m o}$ 10.836. In: de 9 de janeiro de 2004. cria o programa bolsa família e dá outras providências. Diário Oficial da União; 2004.

2. Portaria Interministerial N. Dispõe sobre as atribuições e normas para a oferta e o monitoramento das ações de saúde relativas às condicionalidades das famílias beneficiárias do Programa Bolsa Família. Diário Oficial da União. 2004;18 (2.509, de 18 de novembro de 2004).

3. da Cidadania, M.: Guia para Acompanhamento das Condicionalidades do Programa Bolsa Família. Secretaria Nacional de Desenvolvimento Social. $1^{\text {a }}$ edição atualizada (2020)

4. Executivo S. Avaliação de impacto do programa bolsa família. Centro de Desenvolvimento e Planejamento Regional-Cedeplar/UFMG. Secretaria de Avaliação e Gestão da Informação. Ministério do Desenvolvimento Social e Combate à Fome (2007)

5. Rasella D, Aquino R, Santos CA, Paes-Sousa R, Barreto ML. Effect of a conditional cash transfer programme on childhood mortality: a nationwide analysis of Brazilian municipalities. Lancet. 2013;382(9886):57-64.

6. Boccolini PMM. Covac: the role of social media, bolsa familia program, and primary health care in vaccination coverage for children under five in brazil. Tech. Rep. https://doi.org/10.7303/syn25148356 (2021)

7. Boccolini CS. Breastfeeding in brazil in the matreci model: Mapping, trending, clustering, and impact. Technical report, https://doi. org/10.7303/syn25049520 (2021)

8. Baroni L, Alves R, Boccolini C, Salles R, Gritz R, Paixão B, Boccolini P. Database on the coverage of the Bolsa-Familia conditioning cash-transfer program. Brazil, 2005 to 2021. Synapse: https://doi.org/10.7303/syn25 884313 (2021)

\section{Publisher's Note}

Springer Nature remains neutral with regard to jurisdictional claims in published maps and institutional affiliations.

Ready to submit your research? Choose BMC and benefit from:

- fast, convenient online submission

- thorough peer review by experienced researchers in your field

- rapid publication on acceptance

- support for research data, including large and complex data types

- gold Open Access which fosters wider collaboration and increased citations

- maximum visibility for your research: over $100 \mathrm{M}$ website views per year

At BMC, research is always in progress.

Learn more biomedcentral.com/submissions 